\title{
CONSIDERAÇÕES SOBRE O EMPRESARIAMENTO DA VIDA EM POLÍTICAS PÚBLICAS PARA A EDUCAÇÃO
}

\author{
$*$ \\ Flávia Cristina Silveira Lemos \\ Universidade Federal do Pará-UFPA - Brasil \\ Dolores Galindo \\ Universidade Federal de Mato Grosso - UFMT - Brasil \\ Maria Lívia do Nascimento \\ Universidade Federal Fluminense - UFF - Brasil
}

\section{Resumo}

Este artigo visa a analisar criticamente o que vem sendo denominado de empresariamento da vida no neoliberalismo, em especial, nas políticas de educação que terminam por produzir lógicas de mercantilização dos direitos de crianças e adolescentes. Enfoca a gestão de riscos, a sociedade de segurança e o governo das condutas, a partir da perspectiva desenvolvimentista psicologizante da educação e da promoção de direitos via conceito de resiliência e empoderamento empreendedor de estilos de vida empresariais. Na segunda parte do texto, por meio de estudos de Foucault, efetuamos a análise de acontecimentos do presente, no Brasil. Problematizamos a política de educação e pesquisa calcada em pedagogias das competências socioemocionais e de empoderamento empresarial de direitos desse grupo social.

Palavras-chave: Empresariamento. Desenvolvimento. Neoliberalismo.Direitos de Crianças e Adolescentes. Dispositivo de Segurança.

\section{Introdução}

Foucault (2008) diagnostica que a economia política global passou a focar a fabricação do sujeito empreendedor entrecruzado ao sujeito de direitos, tendo nos saberes do ambientalismo cognitivista comportamental um de seus suportes de gestão da vida. Em busca desse projeto de sociedade,são colocadas em funcionamento políticas sociais e educativas nas quais as versões psicologizantes utilitaristas, baseadas em uma perspectiva linear do desenvolvimento humano e no cognitivismo comportamental, passaram a ser um eixo central para o governo das condutas no empresariamento de si e dos outros hoje.

Operar uma crítica à maneira como os direitos estão sendo mercantilizados pelo negócio do social e por uma política de gestão da educação, com vistas ao empresariamento de crianças e adolescentes, é uma preocupação neste artigo.No texto que segue, problematizamostramas distintas de saberes e práticas - educação, saúde e proteção social - 
marcadas pela gestão de risco e da aprendizagem como performance e do cuidadocomo rastro filantrópico. Buscamos interrogar o dispositivo de controle social e de modelação de condutas que concorre para criar sujeitos autônomos e que gerem renda com suas práticas educativas, de trabalho, de estudo, no ativismo nas comunidades, na gestão dos relacionamentos sociais e afetivos, por meio de habilidades e competências socioemocionais. O livro de Illouz (2011), $O$ amor nos tempos do capitalismo, assinala o processo de mercantilização dos afetos e relações sociais, na instrumentalização dos mesmos nas práticas profissionais, nos saberes e na gestão dos corpos, na sociedade contemporânea.

Foucault (2008) observa que formar subjetividades empreendedoras é uma prática frequente na atualidade e vem se tornando crucial como governo das condutas, conforme assinala no curso Nascimento da Biopolítica. Guattari (1986), por sua vez,em A revolução molecular,ressalta que,nas semióticas do capitalismo, são convocados fluxos diversos que contemplam desde as tecnologias disciplinares educacionais de base familiarista que cortam os espaços fechados à gestão desindividualizada orientada por senhas e códigos.

Apesar das diferenças entre as análises de Foucault a respeito das políticas de subjetivação próprias ao liberalismo, e a noção de capitalismo mundial integrado,proposta por Guattari, há pontos em comum entre os autores, no que tange à afirmação de que a produção das subjetividades é cada vez mais atravessada pela economia política. Ambos nos oferecem pistas para entender o estímulo contemporâneo à gestão de capacidades e déficitsque tomam a vida de crianças e adolescentes como projeto de futuro utilitariamente em nome da segurança e da defesa social.

O que apontamos aqui, a partir das contribuições foucaultianas e de analisadores do presente,sãoos enlaces forjados entre a defesa de direitos,sobretudo aqueles assegurados pelo Estatuto da Criança e do Adolescente,ea racionalidade do mercado neoliberal, baseada em cálculos de economia familiar, social, previdenciária e de saúde. São enlaces que conduzem à violação de direitos e ao acirramento dos supostos problemas econômicos que sustentam suas práticas. Enlaces que, não raras vezes, conduzem a relatos de uma suposta infelicidade por impossibilidade de atingir as capacidades estabelecidas como encomendasde especialistas no plano das vidas de cada um e no plano dos operadores das políticas públicas.

Efetuar a crítica à gestão mercantilista de direitos e à maneira como a gerência empresarial vem sendo associada à educação básica, à socialização pela família e às políticas sociais de pesquisa e de formação de professores e trabalhadores sociais é um objetivo nosso,nas análises presentes neste artigo. A vida ganhou valor como empreendimento simultaneamente ao desenvolvimento econômico e social de um país e da denominada aldeia Barbarói, Santa Cruz do Sul, n.46, p.<06-21>, jan./jun. 2016 
global, conforme o vocabulário dos assessores dessas políticas, pautado na racionalidade neoliberal do Estado mínimo e do mercado como termômetro da regulação da sociedade de segurança.

Foucault (2008), em Nascimento da Biopolítica, aponta esses aspectos neoliberais que emergem ao final da década de setenta, em vários países, mas que desde os anos quarenta do

século XX vinham sendo elaborados pela Escola de Friburgo, na Áustria, e pela Escola de Chicago, nos EUA. As duas escolas faziam a crítica à intervenção do Estado de Bem-estar Social no mercado e defendiam que o próprio mercado se regulasse. Assim, para essas duas escolas, as políticas sociais deveriam ser apenas compensatórias e não ter cobertura universal. O Estado deveria, no máximo, ser parceiro para subsidiar parte da política pública e atuar como um prestador de regras, na regulamentação da mesma.

Considerando-a em sua dispersão, no neoliberalismo, a difusão de práticas empresariais da vida, que visam a forjar sujeitos empreendedores, pode ser vislumbrada em termos da chamada ao empresariamento de crianças e adolescentes, enquanto empreendedores de si, implicados em uma gestão assistida da sua formação científica e tecnológica.

\section{Práticas de gestão de direitos pelo desenvolvimento e empreendedorismo}

No curso $O$ poder psiquiátrico, Foucault (2006) ressalta que o conceito de desenvolvimento se tornou chave para a psiquiatrização da sociedade. A lentidão e a velocidade do desenvolvimento, o retardo e/ou a parada passam a ser marcadores de avaliação de capacidades psicológicas. O acompanhamento e a gestão dos processos de evolução de fases da existência, caracterizados por determinados atributos, vai ganhando relevância nos diagnósticos de riscos de adoecimentos psicopatológicos e de retardos cognitivos.

A infância foi classificada como inferioridade psicológica,comparada aos outros estágios da vida, conforme os manuais desenvolvimentistas que começam a ser constituídos a partir da virada do século XIX para o XX. Os restos de infância nos jovens e adultos são avaliados como traços de um psiquismo primitivo, passando à gestão psicopedagógica e médico-psicológica (FOUCAULT, 2006).

Foucault (2002), no curso Os anormais, considera a construção do desenvolvimento psicológico como atributo de um suposto sujeito psíquico a ser gerido nos riscos de manifestações de suas possíveis crises e perigos de tornar-se a expressão de práticas classificadas como anormais. A psiquiatria e a psicanálise foram agenciadas, na virada do século XIX para o XX, no governo em defesa da sociedade, no governo antecipado dos desvios sociais. A preocupação com perigos futuros passa a ser alvo da prevenção calculada Barbarói, Santa Cruz do Sul, n.46, p.<06-21>, jan./jun. 2016 
dos denominados fatores de risco de tornar-se anormal e incapaz de governar a própria vida e causar prejuízos e inseguranças para a sociedade.

Assim, a gerência dos processos de desenvolvimento tem importância em uma sociedade de segurança que busca a gestão de riscos como dispositivo de criar condições de existência expandida em oportunidades de normalização e normatização. Por essa lógica, o tratamento de doenças e a punição de infrações, como primeira estratégia, perde a prioridade frente à implantação de outra coerência. As práticas políticas e econômicas almejam a promoção, a prevenção e a garantia de direitos, para evitar prejuízos financeiros, regular as doenças e socorrer desempregados e aqueles que se desviam das funções sociais consideradas corretas.

Essa gerência de riscos é analisada por Castel (1987) enquanto governo das condutas em nome de um comércio das políticas para a infância e juventude e de uma modulação de performances e déficits na produtividade dos corpos.Nessa sociedade de segurança cada vez mais utilitarista, os direitos vão se tornando mercadoria e passam a ser contabilizados como custos e benefícios, na política de educação, de saúde e da assistência social, sobretudo no neoliberalismoque se implanta no final da década de setentado século XX. De acordo com Foucault (2008),essa lógicaganha mais incidência a partir da década de noventa e início do século XXI.

Além do conceito de desenvolvimento, um segundo irá dar mais intensidade à gestão neoliberal das políticas sociais, em especial àquelas dirigidas ao que passa a ser tomado como ciclo de vida. É o conceito de resiliência. A ideia de que toda situação deverá ser motor de superação e aproveitamento máximo de gerenciamento empresarial e criação de renda ganha vulto pela resiliência, definida como capacidade de superar estresses, violações e violências e de enfrentar as mais variadas condições de perdas. Resiliente passará a ser quem aproveita oportunidades oferecidas para se tornar empreendedor e se empoderar frente às iniquidades experimentadas, caso receba políticas de incentivo de crescimento e desenvolvimento humano (OLIVEIRA, 2012).

Desse modo, no liberalismo, um conjunto de práticas ditas empreendedoras, voltadas à infância e aos jovens, ganhará relevância na gestão de riscos, de modo a aumentar potencialidades e expandir capacidades de gerar renda e de se autogovernar, com autonomia, sem oferecer perigos aos outros e a si esem gerar prejuízos à sociedade de segurança.

No Brasil, especificamente, essa lógica vem ganhando vulto desde a abertura à mundialização da economia e da cultura, da privatização de muitas das políticas públicas, do aumento de transferência da gestão e financiamento de políticas sociais para o denominado Barbarói, Santa Cruz do Sul, n.46, p.<06-21>, jan./jun. 2016 
terceiro setor e da divisão de responsabilidades em parcerias públicas e privadas na promoção, defesa e garantia de direitos de crianças e adolescentes.

A inserção de medidas psicologizantes na educação básica opera na lógica da pedagogia das competências e habilidades e enfatiza processos de estigmatização social e econômica, hierarquizando as dimensões sociais e afetivas de crianças e jovens. Objetiva-seusar as informações e avaliações realizadas como investimentos e empreendimentos econômicos e políticos, porum currículo baseado em uma perspectiva neoliberal e utilitarista tecnicista, bem como pelo incentivo à participação da sociedade civil na forma de organizações não governamentais e das universidades como entidades de pesquisa.

A conclamação à participação de organizações da sociedade civil, da universidade e das famílias, vistas como entidades ainda nucleares em torno das quais é possível articular intervenções, preserva uma divisão na qual o Estado, ao mesmo tempocada vez mais reduzido, termina por efetuar-se como pretenso provedor de bem-estar. A suposta necessidade de ser protegido se dá pelas condições que colocam alguns segmentos como pedintes ou necessitados de políticas públicas - os miseráveis, ditos infelizes ou, simplesmente, seres em desenvolvimento potencialmente perigosos - nestes últimos se incluem as crianças e adolescentes empobrecidos e considerados em risco e vulneráveis.

Um analisador dessa articulação e segmentação social pode se encontrado na recente chamada pública dirigida aos programas de pós-graduação em educação, psicologia, psicopedagogia e áreas afins. Trata-se do Edital Programa de Apoio à Formação de Profissionais no campo das competências socioemocionais, no Edital N. 044/2014 (CAPES, 2014). As fontes de financiamento provêmde uma fundação empresarial privada, de uma agência multilateral e do governo federal, o que contribui para ampliar a pesquisa, mas também solidifica a ciência brasileira como veículo para a redução de impostos associada à chamada responsabilidade social.

No dia 25 de maio de 2014, foi assinado um protocolo de intenções de parcerias entre a CAPES e o Instituto Ayrton Senna, promovido pelo Ministério da Educação (MEC), pelo Instituto Nacional de Estudos e Pesquisas Educacionais Anísio Teixeira (INEP) e pela Organização para a Cooperação e Desenvolvimento Econômico (OCDE). Esse documento foi assinado em um evento, em São Paulo, nomeado "Fórum Internacional de Políticas Públicas: Educar para as competências do século XXI".

O Instituto Ayrton Senna foi criado em 1994, em uma iniciativa do falecido piloto de Fórmula I, Ayrton Senna, tricampeão mundial. O objetivo desse instituto é fomentar a educação de estudantes que tenham um potencial, de acordo com o Instituto, para atuar Barbarói, Santa Cruz do Sul, n.46, p.<06-21>, jan./jun. 2016 
profissionalmente e responder às exigências culturais, econômicas, políticas para o século XXI. Desde 2004, passa a integrar a Cátedra da UNESCO, contribuindo para a difusão do que denomina soluções para o desenvolvimento humano na educação básica e, assim, auxilie para que o Brasil atinja as metas acordadas com a Organização das Nações Unidas (ONU), para o alcance da qualidade da educação para crianças e jovens. O Instituto define da seguinte maneira suas atividades e a relevância das mesmas:

\begin{abstract}
Anualmente o Instituto Ayrton Senna capacita 64 mil educadores e seus programas beneficiam diretamente cerca de 2 milhões de alunos em mais de 1.200 municípios nas diversas regiões do Brasil. Financiado com recursos próprios, de doações e de parcerias com a iniciativa privada, o Instituto dispõe às administrações públicas, gratuitamente, serviços de gestão do processo educacional que incluem diagnóstico e planejamento, formação de gestores e educadores, desenvolvimento de soluções pedagógicas e tecnológicas inovadoras, tudo articulado de forma a promover uma educação integral para o pleno desenvolvimento de crianças e jovens em suas múltiplas competências. Os resultados impactantes de suas tecnologias e práticas bem sucedidas fazem do Instituto uma referência para a elaboração de políticas públicas. (INSTITUTO AYRTON SENNA, 2014, s/p).
\end{abstract}

As características denominadas competências socioemocionais, citadas por essas instituições, são: perseverança, colaboração, autocontrole, curiosidade, criatividade, amabilidade, abertura às novas experiências, estabilidade, extroversão, resiliência, responsabilidade, otimismo e confiança. A visão em pauta está relacionada a alguns saberes de psicologia e à economia na educação. Há uma preocupação em desenvolver ferramentas para medir e avaliar essas competências na escola e cruzar taisdados com o futuro desses estudantes, em diferentes contextos após o término da educação básica (INSTITUTO AYRTON SENNA; UNESCO, 2013).

Para os participantes do convênio e seus assessores, essas competências deverão ser estimuladas pela escola, com o objetivo de promover o desenvolvimento integral de crianças, adolescentes e jovens.Vê-se um negócio do socialem jogo na organização desse Programa, pois se instala a chamada parceria do setor público com o privado, com o entrecruzamento neoliberal entre uma agência de pesquisa do Estado com um Instituto e uma organização multilateral. Curiosa e nada ingênua é a participação deste organismo internacional de fomento ao desenvolvimento econômico,na cooperação de pesquisas e na formação de professores da educação básica que irão gerir as chamadas competências socioemocionais.

Larrosa (1994) problematiza as práticas de si que passaram a ser realizadas nas escolas, contemporaneamente, com vistas à gestão dos capitais humano, relacional e afetivo. A gestão disciplinar dos corpos e a biopolítica da vida das populações implicou, nesse sentido, segundo 
Foucault (1999; 1988), a individualização e a totalização dos corpos em processos de gestão, com o objetivo de deles extrair produtividade, lucro, controle e docilidade política. O poder disciplinar, que surge no século XVII, examina os corpos, controla-os no tempo e no espaço, vigia-os e os sanciona, de acordo com Foucault (1999). Além disso, incita condutas e prescreve modos de ser, individualiza muito mais do que massifica e cria um sistema de repartição da multiplicidade, extraindo lucro e potência das singularidades.

A liberdade disciplinar, constitutiva do modo indivíduo de ser, passou a ser produtiva de autonomia, de cidadãos livres e responsáveis, autorreflexivos e que se avaliam em função de normas sociais. Com efeito, o estudante é convocado a pensar em sua autoestima, seu autoconceito, em sua identidade e na consciência de si, por meio de práticas psicopedagógicas que são tecnologias do eu na educação. Esses exercícios de si de autogoverno e autocontrole são da ordem do que os pesquisadores brasileiros e docentes estão sendo convocados a realizar, conforme o edital da CAPES e as recomendações da UNESCO e do Instituto Ayrton Senna.

Larrosa (1994) analisou criticamente essa indução de uma educação moral sociopessoal e interroga como a pedagogia se apropriou da psicologia social do desenvolvimento, da psicologia clínica individual e da educação. Dessa maneira, a educação escolar ganha estatuto de mediadora de processos de busca de autoconhecimento, de julgamento de si e de autoavaliação, conforme podemos verificar abaixo:

\footnotetext{
No vocabulário pedagógico - esse conjunto de palavras amplo, indeterminado, heterogêneo e composto pela recontextualização e o entrecruzamento de regimes discursivos diversos - utilizam-se muitos termos que implicam algum tipo de relação do sujeito consigo mesmo. Alguns exemplos poderiam ser "autoconhecimento", "autoestima", "autocontrole", "autoconfiança", "autonomia", "auto-regulação" e "autodisciplina". Essas formas de relação do sujeito consigo mesmo podem ser expressadas quase sempre em termos de ação, com um verbo reflexivo: conhecer-se, estimar-se, controlar-se, impor-se normas, regular-se, disciplinar-se, etc. (LARROSA, 1994, p. 38).
}

A pedagogia é convidada a tornar-se terapêutica e medicalizante. Como evidencia Michel Foucault (2013, p.370), organizações como "Anistia Internacional, Terres des Hommes, Médicos do Mundo são iniciativas que criaram este direito novo: aquele dos indivíduos despojados de intervirem", subjetivados como infantis e incapacitados, em risco e em débito de aprendizagem e desenvolvimento com vistas à cidadania e à autonomia.

Está-se diante de uma gestão das subjetividades como capital afetivo, simbólico e social, em nome da educação como empresa para o desenvolvimento humano e formação 
gerencial dos comportamentos, afetos, relações e crenças como direito e meta nos indicadores nacionais e mundiais do empresariamento da vida em todas as instâncias. Deleuze (1992) fez essa crítica, ao tratar analiticamente do modo como tudo é transformado em mercado a funcionar como empresa que oferece e vende serviços. A educação passou a operar como um comércio de informações e de afetos em formato de competências técnicas e investimentos.

O conceito de empoderamento tem sido utilizado pelas ONGs e organizações que atuam em contextos de desenvolvimento internacional (CARNEIRO, 2004). Emerge em inglês como empowerment, visando a administrar utilitariamente as motivações, competências e habilidades chamadas de afetivas e sociais, tanto individualmente quanto coletivamente, de grupos que sofreram com os processos de desigualdade social e econômica, advindos de situações consideradas de vulnerabilidade, em suas histórias de vida (CUNHA; CUNHA, 2002; IORIO, 2002).

A instrumentalização desses grupos se tornou o negócio do social, para autores tais como Donzelot (1986), Foucault (1988; 1999; 2006; 2008), Castel (1987) e Bauman (1999; 2005). Esse negócio do social traz a tutela dos grupos subalternizados e memorizados em suas possibilidades de governar-se, como marca na chamada gestão de riscos, e apresenta uma solução de ensiná-los a gerir-se, mas pela lógica empresarial no chamado empoderamento e na capitalização dos afetos, das crenças e relações sociais que os mesmos venham a realizar. Todas as práticas passam a ser pensadas como oportunidades para negócios e investimentos lucrativos ou potencialmente de sê-lo em algum momento.

Deleuze (1992) havia apontado, nas sociedades de controle, a partir da segunda metade do século XX, a lógica de operação do marketing do capitalismo de especulação baseado em relações de consumo, investimento e troca/comércio de serviços entre seus usuários, os quais também poderiam ofertar trabalhos variados, modulados por perspectivas empresariais.

Uma iniciativa da Organização das Nações Unidas para a Educação, Ciência e Cultura (UNESCO), que pode ser vista em seus documentos, vai nessa direção,no que se refere à educação, cultura e pesquisa. Trata-se do incentivo a tornar capital o social, o cultural e o humano, em um mercado de direitos de crianças e adolescentes.

A proposta é de agenciá-lospela racionalidade empresa e geração de renda com a educação em direitos e pelo denominado empoderamento de crianças, adolescentes e jovens, em prol de suas comunidades e de si, a fim de que aprendam a ativar seu desenvolvimento e gerenciar suas vidas com autonomia e acesso a oportunidades no mercado. No Relatório Jacques Delot (UNESCO, 2006),há aprescrição deuma educação para aprender a ser, para aprender a conviver, para aprender a aprender e para aprender a fazer.

Barbarói, Santa Cruz do Sul, n.46, p.<06-21>,jan./jun. 2016 
O aprender a aprender pretende formar para a autonomia, iniciativa, flexibilidade e para a formação continuada. O aprender a ser objetiva educar para além da escolarização, ao propor que a educação opere a modelagem de sujeitos de direitos e econômicos simultaneamente como empreendedores e investidores. O aprender a conviver passou a acionar a produção de sociabilidades capitalizadas, da convivência entre dispositivo de segurança pela noção de educação e cultura de paz e, ainda, como gerador de empreendimentos.Já o aprender a fazer visa à preocupação de educar pelo trabalho, ensinar a trabalhar pela escola e tornar o ensino mais técnico e instrumental, pragmático, no aspecto instrumental do neoliberalismo.

Há relatórios da UNESCO (2002; 2003; 2006; 2008) enfatizando a relevância de formar os jovens para que sejam protagonistas em suas comunidades e auxiliem no voluntariado, em projetos sociais de direitos de crianças, tais como em creches ofertadas no bairro, ajudando em aulas de reforço gratuitas, em cursinhos das associações de bairro e oficinas de esportes. Nesses relatórios, o incentivo à participação social é uma maneira de gerir riscos e perigos, ao prevenir situações de envolvimento dos jovens em violência, infrações e influências que os assessores da UNESCO consideram negativas, nas vivências nas ruas.

De acordo com esse organismo multilateral, envolver os jovens nos protagonismos é efetivar o capital social e o capital humano, simultaneamente pelo ativismo em direitos e pela via da formação de competências socioemocionais empreendedoras e do controle social das políticas públicas. O uso da energia do jovem em prol da comunidade é calculado inclusive em termos de impacto no Produto Interno Bruto (PIB) do país, nas tabelas e indicadores estatísticos usados pela UNESCO.

O Fundo das Nações Unidas para a Infância (UNICEF), articuladamente com entidades, institutos, fundações, assessores de vários órgãos, organismos bilaterais e multilaterais, bancos internacionais e ONGs, tem publicado, anualmente, relatórios sobre a situação da infância e adolescência brasileiras. Com esses relatórios, almeja intervir nas políticas de proteção de crianças e adolescentes, no Brasil, operando prescrições e recomendações definanciamento do sistema de garantia de direitos, atuando na criação de projetos e programas dirigidos às situações avaliadas por essa agência como de risco e vulnerabilidade, a serem implantados no país estrategicamente e de acordo com os assessores os quaisatuam nos escritórios do UNICEF em Brasília e nas demais capitais brasileiras.

Nos relatórios do UNICEF (2001; 2002; 2006), é comum o entendimento de que o financiamento de políticas para crianças e adolescentes é um investimento e não um gasto. São frequentes correlações entre custo e benefício,na oferta de programas que tomem o Barbarói, Santa Cruz do Sul, n.46, p.<06-21>,jan./jun. 2016 
cuidado na proteção da infância e adolescência como oportunidades de desenvolvimento social, econômico e político do país. Cada mínima política voltada para crianças e adolescentes se torna uma chance para realizar negócios e empreender a criação de subjetividades empresariais de si e dos outros.

Parao UNICEF, a infância é considerada a primeira e a adolescência a segunda janela de oportunidades para realizar investimentos, na perspectiva que os mesmos darão retornos na geração de renda, na inovação em tecnologias e na produtividade. A prevenção futura de situações de violência, de adoecimentos e do cometimento de infrações também é calculada por essa agência, enquanto um dispositivo de segurança em prol do que vem sendo secularmente chamado de futuro da nação (RIZZINI, 1997).

As práticas de empoderamento das quais vimos falando pressupõem a colocação de segmentos sociais merecedores de recebê-las ou de delas serem partícipes, atualizando uma fábrica de incapacitados a capacitar, de infelizes a potencializar, de vulneráveis a serem convertidos em proativos. A pedagogia das competências é um saber e conjunto de práticas que atua como operador para essas políticas, fornecendo legitimidade e docilidades para ações sociais que, de uma maneira sutil, atualizam as cruzadas educativas da filantropia.

\section{Pedagogia das competências: um capacitar que pressupõe incapacitados permanentes}

A noção de que agir sobre iniquidades nas violações de direitos e prevenir as ameaças das ocorrências das mesmas é uma prática de empreendedorismo de um país que busca se desenvolver pela promoção do desenvolvimento das crianças e adolescentes. Essa é uma preocupação que se materializa nos relatórios do UNICEF, permanentemente. Garantir direitos é analisado pelo crivo de uma educação baseada em competências e habilidades de cuidado parental para o ensino do acesso às oportunidades de crescimento e desenvolvimento humano, de acordo com as premissas normalizadas e normatizadas do que tem sido designado pelos especialistas como proteção e defesa social.

Nesse aspecto, Larrosa (1994) opera a crítica a essa pedagogia moral, pois nela o estudante na escola é modelado para ser cidadão, a se tornar justo, responsável, verdadeiro, exemplar, flexível, estável, solidário, consciente de suas obrigações legais, ousado em realizar investimentos e empreendedor de seus sonhos com iniciativa. Por isso, Ramos (2001) declara que a pedagogia das competências é adaptacionista e visa a preparar indivíduos para aceitarem as condições colocadas no mercado de empregos instáveis, de serem flexíveis às perdas de direitos trabalhistas como o trabalho provisório por projetos, a submeter-se ao 
subemprego e às regras do mercado, na educação e no trabalho. Essa pedagogia promete autonomia com docilidade, liberdade e segurança baseada na lógica do mercado dos mínimos atos educativos, afetivos e sociais, tornando-os instrumentos de capitalização da vida, permanentemente.

Araújo (2004) assinala que a pedagogia das competências emerge aliada ao novo contexto do mercado de trabalho e do neoliberalismo, desde 1970. Nasce voltada à gestão das capacidades humanas e à sua instrumentalização, em uma educação profissional, relacionada aos saberes e ao saber fazer e saber ser. Baseia-se no individualismo, no racionalismo e no neopragmatismo, procurando agir a partir da flexibilidade do trabalho, dos direitos e do capitalismo especulativo de serviços. Foi apropriado um aporte no modelo das competências do cognitivismo-comportamental, forjado na modelação de performances e busca do que denominam eficácia na educação e no trabalho. Foi articulada à Teoria do Capital Humano e, posteriormente, ao modelo de gestão do trabalho dos Círculos de Controle da Qualidade, em 1990.

Araújo (2004) enfatiza,ainda, que essa pedagogia se volta para formar alguém a ser capaz de algo tecnicamente. Opera pela psicologia cognitivista-comportamental e ganha vulto no Brasil, em 1990, na política de formação e nas demais políticas públicas e privadas. Objetivaforjar seres com autocontrole e autoconsciência, ou seja, uma noção de governar-se pela lógica de vida empreendedora como valor e sujeitar-se ao mercado em suas alterações e efeitos, modelando-se a ele todo o tempo.

Nesse sentido, as competências e habilidades são associadas aos processos de desenvolvimento afetivo e social na gestão dos direitos, em nome de um protagonismo/empoderamento utilitário, produtivo e dócil. Os riscos de fugir desse eixo são antecipadamente regulados pelas políticas de segurança e compensatórias, com maior intensidade de disciplinamento das condutas e de regulação da vida dos grupos desobedientes, indóceis à normalização e à normatização do mercado neoliberal, na racionalidade empreendedora.

Frente a essas práticas, é possível compreender porque Chauí (2011) ressalta como o discurso competente e a fala autorizada de especialistas desqualificam outras falas. $\mathrm{O}$ discurso competente retira a capacidade e torna os corpos incapazes. Desse modo,pode geri-los com uma promessa de felicidade e satisfação, obviamente nunca cumprida, já que é uma ilusão e uma ficção fabricada para alimentar o mercado das promessas de reforma da escola e redenção da sociedade pela técnica em mãos de especialistas da felicidade, tal como nos alertou Illouz (2011), ao tratar do amor nos tempos do capitalismo.

Barbarói, Santa Cruz do Sul, n.46, p.<06-21>, jan./jun. 2016 
Em consonância com esse argumento, Foucault (2004), em A ordem do discurso, também destacou as práticas que forjam uma seleção dos discursos na educação, nas editoras, nas sociedades dos discursos, nos dogmas, nas disciplinas e nos comentários, dispositivos de controle social dos corpos. Os saberes se tornam valorizados, na medida em que passam a entrar na ordem econômica e na política de controle discursivo como investimentos. Assim, são articulados com as subjetividades educadas para viverem como empreendedoras de si e dos outros, desde que obedientes à lei e à ordem, no Estado Democrático de Direito atual.

\section{Considerações finais}

A pedagogia das competências e habilidades individualizam a educação e o trabalho, tornando-os mercado de afetos e estabelecendo relações sociais para constituir subjetividades empresariais as quaisse autogovernam pela racionalidade neoliberal e utilitarista e pela fabricação de corpos úteis, dóceis, produtivos e empresariados em seus afetos e relações.

Adocilização política, marcada pelos interesses econômicos de tornar o campo dos direitos um mercado, é mais um intolerável do nosso presente, no qual estamos enredados como cientistas e professores. Não há lugar neutro de crítica e pouco nos serve a indignação vazia e um sentimento tido como nobre, que alimenta as práticas de filantropia e justifica uma prática de gerenciamento da vida.

Vale operar a crítica às políticas que visam a importar escalas e teorias de avaliação socioemocional. O crescimento da pedagogia das capacidades e da avaliação em larga escala de habilidades cognitivas foi questionado pela Associação Nacional de Pós- Graduação em Educação - ANPed- em carta aberta publicada em 2014 (ANPED. 2014). Quiçá as Associações Científicas sejam uma via para atuação política crítica no novo cenário de gerenciamento da vida, por permitirem o diálogo com as instâncias de financiamento e de políticas gestoras da produção da formação e do conhecimento, juntando-se ao chamado terceiro setor, o qual se vê cada vez mais esmagado e preendido num sobrevivencialismo, já que as verbas requerem alianças tácitas.

Não somos contrários ao plano da promoção e da garantia de direitos. Buscamos problematizar aqui quais são esses direitos e que políticas públicas os sustentam. Sobretudo, o que questionamos é a gestão dos direitos como políticas compensatórias, desenvolvimentistas, utilitaristas, tutelares, neoliberais e baseadas em pedagogias tecnicistas como a de competências e habilidades, que atravessam a educação e a assistência social, recortando linhas de financiamento, saberes e competências. 


\title{
CONSIDERATIONS EMPREENDEDORISM IN PUBLIC POLICIES FOR EDUCATION
}

\begin{abstract}
This article aims to critically analyze what has been called the entrepreneurship of life in neoliberalism, especially in education policy that eventually produce logic of commodification of the rights of children and adolescents. Risk management, the security company and the government of pipelines from the psychologizing developmental perspective of education and promotion of rights via concept of resilience and entrepreneurial empowerment of business lifestyles. In the second part of the text by Foucault's studies, we performed the analysis of current events in Brazil. It questions the education policy and research modeled on pedagogies of socio-emotional skills and business empowerment rights of this social group.
\end{abstract}

Keywords: Entrepreneurship. Development. Neoliberalism.Rights of Children and Adolescents.Safety Device.

\section{CONSIDERACIONES CRÍTICAS SOBRE EL ESPÍRITU EMPRESARIAL EN LAS POLÍTICAS PÚBLICAS PARA LA EDUCACIÓN}

\section{Resumen}

Este artículo tiene como objetivo analizar críticamente lo que se ha llamado el espíritu empresarial de la vida en el neoliberalismo, sobre todo en la política educativa que eventualmente producir la lógica de la mercantilización de los derechos de los niños y adolescentes. La gestión del riesgo, la empresa de seguridad y el gobierno de tuberías desde la perspectiva del desarrollo psicologización de la educación y promoción de los derechos a través de concepto de resiliencia y empoderamiento empresarial de los estilos de vida de negocios. En la segunda parte del texto por los estudios de Foucault, se realizó el análisis de los acontecimientos actuales en Brasil. Cuestiona la política educativa y la investigación inspirado en las pedagogías de habilidades socio-emocionales y derechos de empoderamiento de negocios de este grupo social.

Palabras clave: Emprendimiento. Desarrollo. El neoliberalismo. Derechos de los Niños, Niñas y Adolescentes. Dispositivo de seguridad.

\section{Referências}

ANPED. Carta. Disponível em: http://www.anped.org.br/news/carta-aberta-sobre-avaliacaoem-larga-escala-de-habilidades-nao-cognitivas-de-criancas-e-jovens. Acesso em: 05 de dezembro de 2014.

ARAÚJO, R. M. de L. As referências da Pedagogia das Competências. Perspectiva, Florianópolis, v. 22, n. 02, p. 497-524, jul./dez. 2004. 
BRASIL. CAPES. Edital Programa CAPES Competências Socioemocionais. Disponível em:http://www.capes.gov.br/educacao-basica/programa-capes-competenciassocioemocionais. Acesso em: 12 de dezembro de 2014.

BAUMAN, Z. Globalização: as consequências humanas. Rio de Janeiro: Zahar, 1999.

CARNEIRO, R. Planejamento na esfera pública: fundamentos teóricos, possibilidades e limites operacionais In: CARNEIRO, C. B. L.; COSTA, B. L. D. (Org.).Gestão Social: o que há de novo? Belo Horizonte: Fundação João Pinheiro, 2004. v. 2.p. 47-68.

CASTEL, R. A gestão de riscos: da pós-antipsiquiatria à pós-psicanálise. Rio de Janeiro: Francisco Alves, 1987.

CHAUÍ, M. Democracia e cultura: o discurso competente e outras falas. Rio de Janeiro: Cortez, 2011.

COSTA, J. F. A ética democrática e seus inimigos. In: BETTO, F.; VERÍSSIMO, L. F.; COSTA, J. F.; SOARES, L. E. (Org.). O desafio ético. Rio de Janeiro: Garamond, 1997. P. 67-79.

CUNHA, E. P.; CUNHA, E. S. M. Políticas Públicas Sociais. In:CARVALHO, A.et al. (Org.). Políticas Públicas. Belo Horizonte: Ed. UFMG; Proex, 2002.

DONZELOT, J. A polícia das famílias. Rio de Janeiro: Graal, 1986.

FOUCAULT, M. Microfísica do poder. Rio de Janeiro: Graal, 1979.

FOUCAULT, M. História da sexualidade I: a vontade de saber. Rio de Janeiro: Graal, 1988.

FOUCAULT, M. Vigiar e Punir: uma história da violência nas prisões. Petrópolis/RJ: Vozes, 1999.

FOUCAULT, M. O nascimento da biopolítica. São Paulo: Martins Fontes, 2008.

FOUCAULT, M. Os Direitos dos Homens em face dos governos. Ditos e Escritos, vol. VII, p. 369-370.

GUATTARI, F. A revolução molecular. São Paulo: Brasiliense, 1985.

ILLOUZ, E. O amor nos tempos do capitalismo. Rio de Janeiro: Zahar, 2011.

INSTITUTO AYRTON SENNA, 2014. Disponível em:

http://senna.globo.com/institutoayrtonsenna/home/index.asp. Acesso em: 11 de dezembro de 2014.

INSTITUTO AYRTON SENNA; UNESCO. Educação para o século XXI. São Paulo, 2013. Disponível em: http://educacaosec21.org.br/wpcontent/uploads/2013/07/COMPET\%C3\%8ANCIAS-SOCIOEMOCIONAIS_MATERIALDE-DISCUSS\%C3\%83O_IAS_v2.pdf. Acesso em: 12 de dezembro de 2014. 
IORIO, C. Algumas considerações sobre estratégias de empoderamento e de direitos. In: ROMANO, J.; ANTUNES, M. (Org.). Empoderamento e direitos no combate à pobreza. Rio de Janeiro: ActionAid Brasil, 2002. p. 21-44.

LARROSA, J. Tecnologias do eu e educação. In: SILVA, T. T. O sujeito da educação. Petrópolis: Vozes, 1994. p.35-86.

OLIVEIRA. S. Política e resiliência - apaziguamentos distendidos. Ecopolítica, n. 4, p. 05$129,2012$.

RAMOS, M. N. Pedagogia das competências: autonomia ou adaptação? São Paulo: Cortez, 2001.

RIZZINI, I. O século perdido. Raízes históricas das políticas públicas para a infância no Brasil. Rio de Janeiro: EDUSU/AMAIS, 1997.

UNESCO - Organização das Nações Unidas para a Educação, a Ciência e a Cultura.

Construção e identidade: as idéias da Unesco no Brasil. Brasília: Jorge Werthein/UNESCO, 2002.

UNESCO - Organização das Nações Unidas para a Educação, a Ciência e a Cultura. Por uma economia com face mais humana. Brasília: UNESCO, 2003.

UNESCO - Organização das Nações Unidas para a Educação, a Ciência e a Cultura.

Relatório Jacques Delors. Educação para o século XXI: um tesouro a descobrir. Brasília: Cortez/MEC/UNESCO, 2006.

UNESCO - Organização das Nações Unidas para a Educação, a Ciência e a Cultura. Mais ética, mais desenvolvimento. Brasília: UNESCO, 2008.

UNICEF. Situação da Infância Brasileira. Brasília: UNICEF, 2001.

UNICEF. Fazer Valer os Direitos das Crianças e dos Adolescentes. Brasília: UNICEF, 2002.

UNICEF. Competências familiares na atenção às crianças de até 6 anos: avaliação em oito comunidades. Brasília: UNICEF, 2005.

Data de recebimento: 22/01/2015

Data de aceite: 24/01/2017

\section{Sobre as autoras:}

Flávia Cristina Silveira Lemos possui graduação em Licenciatura, bacharelado e formação em Psicologia pela Universidade Estadual Paulista Júlio de Mesquita Filho (UNESP - 1999), mestrado em Psicologia pela Universidade Estadual Paulista Júlio de Mesquita Filho (UNESP - 2003) e doutorado em História pela Universidade Estadual Paulista Júlio de Mesquita Filho (UNESP - 2007). Professora de psicologia social/UFPA. Bolsista de produtividade em pesquisa CNPQ PQ2. Endereço Eletrônico: flaviacslemos@ gmail.com 
Dolores Galindo é psicóloga-UFPE. Mestre e Doutora em Psicologia Social-UFMT na graduação e pós-graduação. Endereço Eletrônico: dolorescristinagomesgalindo@gmail.com

Maria Lívia do Nascimento é psicóloga. Mestre em Psicologia. Doutora em Psicologia SocialUFF na graduação e na pós-graduação. Endereço Eletrônico: mlivianascimento@ gmail.com 